\title{
A Sociologia rural no Brasil: entre escravos do passado e parceiros do futuro ${ }^{1}$
}

AFRÂNIO GARCIA*

\section{Preliminares}

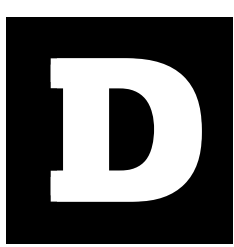

urante a conferência de abertura, pronunciada pelo Dr. José Bengoa, sobre os 25 anos de mudanças na temática dos estudos sobre o universo rural da América Latina, sobretudo em sua vertente hispânica, pudemos ter acesso a um panorama denso das transformações recentes no continente americano. Tendo tido oportunidade de realizar um exercício semelhante para congresso da ANPOCS (Associação Nacional de Pós-Graduação em Ciências Sociais) em outubro último, ${ }^{2}$ em retrospectiva do tratamento da questão agrária no Brasil nas três últimas décadas, gostaria de me ater, nesta oportunidade, ao peso da matriz social hierárquica legada pela plantation colonial.

O tema que proponho discutir aqui é o destino da célebre dualidade entre senhores e escravos, mais precisamente sobre o itinerário diferencial de descendentes dos senhores e descendentes dos escravos, ou ainda, para retomar a formulação famosa de Gilberto Freyre, as transformações

\footnotetext{
* Doutor, École des Hautes Études en Sciences Sociales (EHESS), Paris (França) e Universidade Federal do Rio de Janeiro, Rio de Janeiro, (Brasil).

1 Este foi o texto base de conferência proferida no Congresso da Associação Latino-Americana de Sociologia Rural (ALASRU). Gostaria aqui de agradecer a honra de ter sido convidado a proferir uma das conferências desse Congresso, e, em particular, à Professora Anita Brumer, que demonstrou na prática que a capacidade de auto-exploração das próprias energias é uma das virtudes que os sociólogos latino-americanos compartilham com os camponeses da região. O prazer é tanto maior por ser a Universidade Federal do Rio Grande do Sul, que abriga o evento, local que implantou, desde 1963, pós-graduação em sociologia rural, pioneira, portanto, das inovações institucionais no ensino e pesquisa pós-graduadas, que tanto contribuíram para a renovação das ciências sociais no Brasil desde os anos 1960. Encontrar sempre nos colegas do Rio Grande do Sul o gosto por tratar das questões teóricas mais relevantes, através de pesquisas empíricas rigorosamente formuladas, e a disposição para o diálogo e a crítica aguda e pertinente, tem sido para mim fonte inesgotável de alento.

2 Vide Afrânio Garcia e Mário Grynszpan, "Veredas da questão agrária e os enigmas do grande sertão". In : S. Miceli (org.). O que ler em ciências sociais. São Paulo: ANPOCS, 1999.
} 
da oposição casa-grande e senzala, para melhor poder captar os desafios postos pelo momento presente.

Durante a conferência inaugural, José Bengoa tomou como uma de suas referências centrais o famoso artigo dos antropólogos norte-americanos Eric Wolf e Sidney Mintz - "Haciendas and plantations in the new world"3 - para pensar o destino do poder social dos proprietários de haciendas. No momento dos debates, o sociólogo argentino Miguel Murmis questionou-o sobre se as reflexões anteriormente apresentadas tinham por único referente as "haciendas" ou também incluíam as grandes plantações mais integradas ao mercado internacional; em outros termos, o que se poderia pensar sobre o destino social dos proprietários de plantation - a fração mais integrada ao mercado internacional?

Refletir sobre o campo brasileiro, sobretudo a propósito das transformações do século XX, significa necessariamente tomar por objeto o mundo da plantation, mais precisamente, as grandes plantações de café, de cana de açúcar, de cacau, de algodão, sisal ou variantes. Nesta palestra, dialogarei também com a questão central analisada na brilhante conferência proferida ontem pela Professora Magdalena León sobre a relação entre gênero e a transmissão da propriedade da terra na América Latina e, particularmente, sobre a falsa suposição da família camponesa como totalidade indivisa e homogênea, que impede de abordá-la como rede complexa, não igualitária e que reserva um estatuto subordinado às mulheres nessas redes.

Desejo iniciar, contudo, com um problema de ordem mais geral, válido certamente para toda a América Latina, mas que apresenta contornos mais universais, que transcendem os limites de cada processo histórico de países ou grupos de países singulares: trata-se das condições sociais de possibilidade do individualismo moderno. Em sua locução de abertura, o presidente da ALASRU, Dr Diego Piñero aludiu às análises do sociólogo

3 cf. Eric Wolf y Sidney Mintz, "Haciendas y plantaciones en Meso américa y Las Antillas". In: Florescano (org.). Haciendas, latifundios y plantaciones en América Latina. México: CLACSO/Siglo XXI, 1975. 
francês Robert Castel - Metamorfoses da questão social ${ }^{4}$ - sobre as transformações nos últimos trinta anos na Europa e ao surgimento, com os efeitos sociais do desemprego em massa, a partir dos choques da alta dos preços do petróleo em 1973, de uma nova categoria social: a dos "novos inúteis". Nada melhor para sintetizar as preocupações centrais desse livro de Robert Castel, notadamente no que toca à falência do que ele denomina de "sociedade salarial", do que a epígrafe tomada de empréstimo a Hannah Arendt: "O que temos, diante de nós, é a perspectiva de uma sociedade de trabalhadores sem trabalho, ou seja privados da única atividade que lhes resta. Não se poderia imaginar nada de pior".

Robert Castel, em livro recente, reproduzindo diálogo com Claudine Haroche - Propréié privée, propriété sociale, propriété de soi (Fayard, 2001) - retorna a John Locke e a Louis Dumont sobre o individualismo moderno, para explicitar os suportes, o tecido social, necessários para se comportar como sujeito individualizado, dotado de vontade particular e capaz de leválo à prática. A reflexão aqui compreende a questão da cidadania política, mas a ultrapassa, pois visa pensar para além das tomadas de decisão politicas coletivas: trata-se de conceber o indivíduo portador de desejos e senhor de seus atos, permitindo sua concretização.

Retomando as palavras de Robert Castel:

Tratando-se do indivíduo, o que se escuta constantemente no discurso liberal ou neo-liberal? Que há indivíduos que apenas pedem para se exprimir como tais, para desenvolverem suas capacidades inibidas por restrições de tipo estatal ou burocráticas. Bastaria liberar o indivíduo dessas amarras para que ele se realize integralmente, que se torne mais produtivo sobre o plano econômico, mas que também se realize no plano pessoal. É conceber o indivíduo como se ele estivesse dado uma vez por todas e não dependesse em nada das condições históricas e sociais de sua existência. Por relação - e contra - esta posição sobre a questão do

4 CASTEL, R., 1995. 
indivíduo, deve-se fazer a hipótese que o indivíduo não existe como uma substância e que para existir como indivíduo é imprescindível que tenha suportes, e assim se interrogar sobre o que há "por trás" do indivíduo que the permita existir como tal.

Robert Castel adianta ainda, para especificar a ruptura da generalização da possibilidade de todos se transformarem em indivíduos dotados de livre expressão de suas vontades:

De um ponto de vista histórico a propriedade de si se pensa primeiramente em Locke por oposição ao modelo da dependência e, mais geralmente, ao modelo que Dumont chamaria de sociedade "holista". Ao modelo de sociedade holista, Locke opõe o modelo da independência, que poderíamos traduzir na linguagem filosófica de Kant como "autonomia da vontade". E um indivíduo que pode se determinar ele próprio desde o momento que é capaz de se apropriar da natureza do seu trabalho. Assim ele é proprietário de si mesmo porque tem bens que o colocam fora dessas situações de dependência das pessoas que nada têm, que não podem ser indivíduos por si próprias (p. 15).

Do legado da escravidão em países como o Brasil, ou de formas de subordinação pessoal acarretada por instituições como a encomienda no mundo hispânico, faz parte a presença duradoura da dependência pessoal da maioria da população rural por relação aos proprietários de grandes domínios de terra, traço que marca profundamente a história do século XX. É esta herança histórica do caso brasileiro que busco estudar a seguir. ${ }^{5}$

5 O caráter incompleto da passagem de uma sociedade holista a uma sociedade individualista, para dialogarmos com o vocabulário do antropólogo francês Louis Dumont, é o tema central da nova problemática introduzida pelo antropólogo Roberto da Matta (1979), particularmente o que denominou de "dilema brasileiro" pensando empiricamente a partir do estudo do carnaval, do futebol, do jogo do bicho, como rituais da nacionalidade. Tento aqui dar um tratamento de sociologia histórica a questões que Roberto da Matta vem examinando de forma fecunda e inovadora com os instrumentos da análise estrutural de cosmologias. 
Para tanto, a exposição apresentará quatro partes: na primeira, analiso a grande lavoura como matriz da sociabilidade hierárquica herdada da época colonial. Em seguida, passo em revista os principais fatores responsáveis pela quebra das condições de existência da dominação tradicional. Em terceiro lugar, examino as modalidades de desenraizamento do campesinato brasileiro e a presença maciça, desde meados dos anos sessenta, de indivíduos desprovidos das condições mínimas de existência e que perderam suas referências sociais e culturais, tudo muito característico do que Robert Castel denominou de "individualismo negativo" ou "individualismo por falta" ou "carência". Por último, cabe tratar das mobilizações promovidas pelo movimento dos sem terra e da relevância conquistada pelo tema da "reforma agrária", em busca de formas de novo enraizamento social e cultural de camadas desfavorecidas.

\section{A grande lavoura como matriz da nacionalidade e a posição subordinada do campesinato}

No início do século XX, o espaço físico e o poder social estão concentrados pelos detentores de grandes plantações voltadas para cultivos destinados aos mercados internacionais, particularmente à Europa e aos Estados Unidos da América. Lavouras como café, cana-de-açúcar, algodão, borracha, cacau, fumo são responsáveis por mais de 85 \% das exportações brasileiras, posição que ocupam desde a primeira metade do século XIX (cf. P. Eisenberg, 1977; quadro 1, p. 31). A execução das ordens emanadas das casas-grandes, emitidas por senhores-de-engenho, usineiros ou fazendeiros, supõe o recrutamento de mão de obra sob formas diversas de dominação pessoalizada (cf. M. Palmeira, 1971 e 1976), como nos casos dos moradores de engenho (L. Sigaud, 1980), dos colonos de café (J. S. Martins, 1979) ou dos agregados e vaqueiros do interior do país. Os movimentos da plantation controlam a apropriação do espaço físico: só há desenvolvi- 
mento de campesinato em áreas periféricas ou marginais à "grande lavoura" (cf. B. Heredia, 1979; A. Garcia Jr., 1983) ou expressamente destinadas a fluxos de imigrantes europeus, atraídos por políticas que tinham tanto finalidades econômicas quanto o objetivo de promover o "branqueamento" da população, como se observa no Vale do Itajaí em Santa Catarina (G. Seyferth, 1974) e na Serra gaúcha (J. V. Tavares dos Santos, 1978).

O mundo rural é o quadro da existência da maior parte da população - ainda em 1940, 70\% da população aí residia. Contudo, as regiões de grande lavoura não são interligadas e articuladas, de forma a constituírem circuitos econômicos interdependentes. Para se deslocar das regiões onde o café predominava, como em São Paulo e Rio de Janeiro, para as áreas cacaueiras da Bahia, ou para as áreas canavieiras de Pernambuco, o meio de transporte que se impunha era a navegação de cabotagem. Esta segmentação do território nacional em diferentes regiões, mais voltadas para um porto de exportação do que interligadas por uma malha de sistemas de transporte e de comunicações, fornece uma imagem adequada da diferença que há entre o território nacional como um "arquipélago", cujas ilhas são constituídas pelas diferentes áreas de grandes lavouras ou mineração, e este mesmo espaço físico após a implantação do parque industrial entre os anos 1930-80, visto como um "continente", para lembrar a metáfora cara a Hervé Théry (2000).

Ao final do século XX, é nas cidades que se concentra o grosso da população e a segunda metade do século vai conhecer um movimento contínuo do deslocamento das residências do campo para as cidades: já em 1980 70\% dos contingentes se situam no pólo urbano (em 2000 apenas $22 \%$ residem no espaço rural). O centro dinâmico da economia, com a industrialização acelerada entre 1930 e 1980, e os poderes social, cultural e político vão localizar-se nas grandes metrópoles, com a reestruturação do Estado nacional e a ampliação de suas áreas de intervenção, com a criação de Universidades e a reorganização do sistema de ensino em bases 
nacionais, com o surgimento de partidos políticos e movimentos associativos em escala especificamente nacional. As formas de sociabilidade características do mundo rural se encontram crescentemente referidas a estilos de vida, concepções do mundo, processos de decisão e modalidades de trabalho que se elaboram e se modificam além de seus horizontes. Assim também não é de se estranhar que, ao final do século $X X$, haja disputas explícitas sobre os próprios significados a atribuir à expressão "futuro do mundo rural", ou ainda sobre o significado da noção de "modernidade", para pensar as transformações do campo e, sobretudo, as relações entre a cidade e o espaço rural. As vias de transformação das relações sociais no campo não seguem itinerários inexoráveis, há caminhos alternativos, como demonstra o debate recente que salienta o desenvolvimento da "agricultura familiar" em paralelo ao da "agricultura empresarial", ou ao crescimento do "complexo agro-industrial" ou de "agronegócio". De qualquer forma, é fundamental observar que o "mundo agrícola" hoje não é mais pensado como um bloco coeso, como uma única corporação implantada ao longo de um imenso território; a representação do mundo agrícola, a imagem de unicidade que se buscava no início do século são hoje atravessadas pela oposição dos agentes concebidos por categorias como "agricultura familiar", "complexo agro-industrial", "agricultura empresarial", "agricultura tradicional", "agronegócio", a demonstrar a intensidade da competição por terra, por recursos financeiros, por força de trabalho e, sobretudo, pela legitimidade de designar o futuro das relações no mundo rural e das configurações cidade-campo.

\subsection{A velha plantation, uma instituição total?}

Se as grandes plantações de café, de cana-de-açúcar, de cacau, de algodão, ou fazendas de gado constituem unidades fundamentais dos processos econômicos, sociais, culturais e políticos no limiar do século XX e deitam freqüentemente suas raízes no Brasil colonial, isso não significa, de 
modo algum, que possam ser concebidas como "comunidades rurais isoladas". A relação com a rede de cidades que as interligavam aos portos de exportação é parte integrante das condições de existência de cada grande plantação tomada isoladamente. Considere-se que esses núcleos populacionais são criados para promover atividades destinadas a produzir mercadorias valorizadas no âmbito internacional; assim é que mudanças no sistema de transporte, como a implantação de rede ferroviária em finais do século XIX, tornaram possível a expansão da fronteira agrícola, permitindo que espaços ocupados por mata atlântica fossem apropriados por novas fazendas de café, o que transformou completamente as condições de concorrência entre as "áreas antigas" como o Vale do Paraíba do Sul (cf. S. Stein, 1957) e as áreas novas do planalto de São Paulo (cf. P. Monbeig, 1952; W. Dean, 1977; S. Silva, 1976). Tais mudanças dos circuitos de comercialização alteram tanto a vida quotidiana das grandes plantações e da miríade de médias e pequenas explorações a elas subordinadas quanto provocam a decadência da malha de cidades que constituíam os elos de ligação com os portos e centros administrativos. Certamente a alteração dos circuitos comerciais incidiram nas redes religiosas, culturais e políticas das áreas da antiga colonização, modificando a composição dos participantes dos jogos políticos e culturais, provocando o surgimento de novos templos, novos estabelecimentos de ensino e de cultura, novos centros administrativos e de decisão política nas regiões de ocupação recente. Talvez seja desnecessário enfatizar que nenhum respeito, ou busca de preservação, houve com os grupos ameríndios que ocupavam de forma milenar as terras das frentes pioneiras. Freqüentemente aldeias inteiras foram abatidas, como as florestas das frentes pioneiras.

As grandes plantações constituíram, até meados do século XX, unidades econômicas, sociais, culturais e políticas bastante específicas. Do ponto de vista econômico, esse era o quadro da organização do trabalho agrícola, no qual se combinavam o cultivo de lavouras destinadas ao comércio 
de exportação como o café, a cana-de-açúcar, o algodão, o cacau, etc., com lavouras destinadas, sobretudo, ao abastecimento alimentar da família do proprietário de terras e das diversas famílias de trabalhadores residentes (moradores, colonos, agregados) no domínio, como a mandioca, o milho, o feijão, além da criação de pequenos animais (aves, suínos, ovinos e caprinos). Voltada para produtos destinados a mercados de longa distância, a plantation sempre esteve associada a atividades de beneficiamento de produtos agrícolas que assegurassem a manutenção das qualidades essenciais dos bens vendidos: as instalações próprias à transformação da matéria prima agrícola, como os engenhos-de-açúcar movidos a tração animal ou impulsionados por roda d'água, ou as usinas de açúcar que os substituíram como grandes fábricas em pleno campo (J. S. Leite Lopes, 1976) representaram sempre investimentos materiais de tanta importância e aquisição de conhecimentos de tal envergadura que passaram a símbolo primordial das unidades agroindustriais e marcos do poder dos proprietários de terras, como se observa através da força de expressões como senhores-de-engenho (Antonil, 1982) e usineiros-de-açúcar (Correia de Andrade, 1964). Instalações menos exigentes em capital e know-how como terreiros de secar café, descaroçadoras de algodão e desfibradores de sisal, também sempre foram partes constitutivas do universo da plantation. Havia assim, desde os primórdios da colonização, um "complexo agroindustrial", como nas regiões de cana e de algodão, bem diferente das agroindústrias que serão assim chamadas a partir dos anos 80, como a indústria dos derivados do leite, dos sucos de fruta, ou de abates e transformação de aves e suínos. Até meados do século XX, predominou a associação entre capital fundiário, agrícola e industrial: quem comanda o processo de trabalho exerce seu mando tanto na esfera agrícola como na industrial, é do conjunto de suas atividades que provém seu lucro.

Mas a grande plantação é bem mais do que apenas a unidade de base de um processo agroindustrial; ela é, sobretudo, a matriz da sociabi- 
lidade no mundo rural da primeira metade do século: o grande domínio é a sede das residências dos grandes proprietários - as "casas-grandes" (G. Freyre, 1933) - e também das casas de morada atribuídas às famílias de trabalhadores residentes (M. Palmeira, 1976). É no interior do grande domínio que se exerce a vida familiar, onde se nasce, casa-se, procria-se, por vezes, onde se enterram os mortos. As capelas no interior das "casas-grandes" mais abastadas, ou em suas vizinhanças quando mais imponentes, fazem lembrar que as práticas e cerimônias religiosas agrupam e reordenam os viventes dentro dos domínios ou, ainda, que as práticas religiosas dos subalternos, como no caso do candomblé e do xangô dos descendentes de africanos (R. Bastide, 1958) ou do protestantismo dos colonos do café recrutados entre imigrantes europeus (T. Davatz, 1941) eram objeto de recriminação e censura, quando não eram mantidos sob estrita vigilância, por parte dos proprietários das casas-grandes.

É interessante notar que os modelos de percepção consagrados pela literatura sociológica e histórica dos anos 30 vão enfatizar justamente o caráter fundamental dos padrões sociais herdados do universo colonial e escravagista que se impunham com o crescimento da urbanização e com a aceleração do processo de industrialização do país. No próprio título de sua obra maior - Casa-grande e Senzala -, Gilberto Freyre (1933) assinalava como a sede dos domínios rurais era uma instituição que continuava a operar mesmo após a abolição da escravatura em 1888 e como a reunião de poderes econômicos, religiosos, culturais e políticos em uma só mão funcionava como princípio ordenador do mundo social, recriando, por uma lógica que supõe complementaridade, mas diferença irredutível, o mundo dos descendentes dos senhores das casas-grandes e aqueles dos escravos das senzalas.

De 1936 data também Raízes do Brasil de Sérgio Buarque de Holanda, obra que, ao lado de Casa-Grande e Senzala, irá influenciar toda uma geração de intelectuais, segundo o depoimento de Antônio Cândido (1967). 
Sérgio Buarque também persegue as marcas da hierarquia constitutiva do grande domínio rural construído a partir da escravidão de populações africanas negras sobre a psicologia íntima dos brasileiros; à diferença de Gilberto Freyre, porém, interessa-se por sua projeção na vida pública, no comportamento político, e analisa como constitui um empecilho à construção de um Estado moderno e democrático. O "homem cordial", escravo de suas paixões, não aceita normas que transcendam seus desejos, nenhum espaço público moderno pode assentar-se sobre tais bases. Servo das leis livremente pactuadas contra servo dos desejos individuais de indivíduos habituados a serem servidos por escravos: tal dilema é o brasileiro na construção do Estado, em bases modernas e democráticas.

Também Caio Prado Jr. (1942), para examinarmos a trilogia clássica dos autores mencionados por Antônio Cândido (1967), focaliza o grande domínio rural como unidade de base constituidora da "economia colonial", cuja dinâmica está totalmente presa aos impulsos vindos dos centros internacionais de destino de suas lavouras comerciais. Para esse autor, a construção de uma "economia nacional", em que as indústrias cumpram o papel de novo pólo articulador de todo o sistema produtivo da nacionalidade, implica a superação das principais características imprimidas pelo grande domínio à economia do país. Como para os demais, o mundo urbano que se expandia e se industrializava era portador de novas potencialidades, mas seus dinamismos e seus rumos dependiam de uma reestruturação das formas de operar do universo agrícola. Vê-se assim que, na formulação de alguns dos principais autores dos anos 30, o legado das formas de organização social do mundo rural pesa sobre o presente de uma forma bem mais substancial do que uma simples tradição a ser superada. O próprio esforço que fizeram para estudá-la de forma detalhada, tanto em seus aspectos morfológicos quanto em suas projeções na "psicologia íntima" (G. Freyre, 1933) de cada brasileiro, demonstra que estavam convencidos de que o trabalho de conhecer as estruturas do mundo rural 
tradicional era parte integrante de esforço para pensar novos destinos para a coletividade nacional.

\subsection{Movimentos das grandes plantações}

O exame em profundidade das enormes flutuações de preços nos mercados internacionais dos principais produtos de exportação brasileira como o café (E. Bacha, 1992) e o açúcar (P. Eisemberg, 1977; T. Szmeracsányi, 1979), de finais do século passado até os anos setenta do $X X$, mostra que os movimentos da plantation brasileira apresentou uma grande flexibilidade em relação a tais variações. Pois é justamente na especificidade dos mecanismos de operação de plantation tradicional (M. Palmeira, 1971; E. Wolf e S. Mintz, 1975) que vamos encontrar os fundamentos para compreender sua plasticidade, longevidade e resistência.

A primeira das características da "velha plantation" reside nas formas de recrutamento dos trabalhadores e na infinidade de arranjos práticos que ela permite, para contrabalançar baixas de preços obtidos pela venda das lavouras comerciais. Em verdade, a maior parte da mão-de-obra utilizada pelas plantations era recrutada sob a forma de moradores (M. Palmeira, 1976 e 1979) ou de colonos nas áreas de café (J. S. Martins, 1979; V. Stolcke, 1976); essas formas de seleção e gestão da força de trabalho, implantadas ainda durante a vigência da escravidão como estatuto jurídico (cf. M. Correia de Andrade, 1964; P. Eisenberg, 1972; T. Davatz, 1941) asseguraram a recriação dos poderes dos senhores-de-engenho e dos fazendeiros de café após a abolição da escravatura. Elas supoêm efetivamente que haja contratos, ou seja, acordos de vontades de personagens distintas, acordos entre indivíduos formalmente "livres e iguais" diante do direito, mas esses contratos individuais, diante da brutal assimetria entre os parceiros, instituíam de forma duradoura a submissão de famílias de trabaIhadores às vontades dos proprietários. Ao "pedir morada" (M. Palmeira, 1976), um chefe de família exibia ao senhor-de-engenho que se encontra- 
va destituído dos meios mais elementares de assegurar a subsistência de seu grupo doméstico: nem dispunha de casa-de-morada para abrigar os seus nem possuía terras para trabalhar e fazer trabalhar seus familiares para obter seu sustento. Assim, muito além de um acordo de vontade entre "iguais diante do direito", o ritual de solicitar abrigo em grande domínio rural enfatizava a dessimetria entre o patrão que acolhe um novo cliente e o indivíduo que se desqualifica como homem ${ }^{6}$ ao pedir apoio e proteção: ao entrar na propriedade, todo chefe de família contraía de imediato uma dívida moral com o proprietário, que ultrapassava de muito o valor material dos elementos de vida que eram providos pelo novo patrão.

Os acordos interindividuais entre um grande proprietário e um chefe de família de moradores ou de colonos incidiam numa infinidade de domínios de relações pessoais, em que as prestações de parte a parte tomavam a forma de dons e contradons. Os parâmetros pelos quais são concebidas tais relações nunca são redutíveis apenas aos valores monetários atribuídos em contrapartida do trabalho fornecido. Ante as flutuações adversas dos mercados internacionais das lavouras comerciais, sempre era possível buscar nas contrapartidas das relações morador/senhor-de-engenho ou colono/fazendeiro arranjos que reduzissem o custo monetário do trabaIho a ser efetuado e, portanto, que contribuíssem para preservar a margem de lucro, notadamente a renda monetária, permitindo adquirir bens não produzidos localmente (vestuário, calçado, chapéus, mobiliário, instrumentos musicais, etc.). Igualmente as reconversões dos plantios de lavouras comerciais, ao contrário da propalada inércia da "monocultura" de grande lavoura, como a substituição da cana-de-açúcar ou de café pelo algodão, da cana pelo sisal, pastagens para o gado ou pela cultura do tabaco, ou ainda pela exploração do bicho-da-seda, sempre podiam contar com

6 Lygia Sigaud (1970), ao estudar as representações dos moradores-de-engenho da Zona da Mata de Pernambuco, ressaltou como a categoria de homens se referia unicamente aos senhores-de-engenho e usineiros. Sua dissertação de mestrado teve por título significativo Nação dos homens. 
rearranjos na relação morador/senhor, que permitissem reduzir os investimentos monetários dos grandes proprietários de terras (cf A. Garcia, 1990). O estudo minucioso dos engenhos tradicionais e das fazendas de café e de algodão permitiu observar mecanismos econômicos homólogos aos descritos pelo historiador Witold Kula para as fazendas cerealíferas polonesas entre os séculos XVI e XVIII (cf. W. Kula, 1970; para o Brasil ver B. Heredia, 1989; A. Garcia, 1989): em épocas de queda nos preços internacionais das lavouras comerciais, a produção podia ser expendida para se obter a mesma renda monetária em divisas estrangeiras. Constatou-se ainda que a queda das rendas proporcionadas pela venda dos produtos comerciais da plantation certamente implicava em declínio dos padrões de estilo de vida "cosmopolita" ou calcado nos modelos europeus, dos detentores da plantation, mas, de forma alguma, acarretava necessariamente sua falência: o abastecimento alimentar dos donos e moradores, assim como o da casa-grande, e também a maior parte das construções e equipamentos produtivos, eram assegurados pelo cultivo sistemático de lavouras alimentares e pelo uso dos recursos naturais disponíveis no domínio ou em suas cercanias (cf. B. Heredia, 1989; A. Garcia, 1989).

A compreensão das formas específicas de gestão da grande plantação tradicional é, sem sombra de dúvidas, fundamental para que se entenda sua durabilidade ao longo do século $X X$, mas não menos importante é atentar-se para o trabalho político das elites agrárias, desde o final do século XIX, que resultou na criação e no desenvolvimento de mecanismos institucionais de sustentação de preços das lavouras de exportação (para o café, ver T. Holloway, 1968 e E. Bacha, 1992; para o açúcar, ver T. Szmerecsányi, 1979). A percepção do Brasil como responsável por uma parcela apreciável da oferta mundial de café levou alguns dos maiores produtores, associados a comerciantes de exportação e elites políticas, a tentarem forçar uma evolução mais favorável dos preços internacionais desse produto mediante práticas de controle da oferta; são as políticas 
assim concebidas e postas em prática por iniciativa de cafeicultores paulistas que introduziram o neologismo valorization no jargão das bolsas mundiais de mercadorias (cf. T. Holloway, 1968; E. Bacha, 1992).

É notável que instituições públicas de regulação do comércio do café tenham tido seus equivalentes, a partir de 1930, para as demais lavouras de exportação, particularmente no tocante à cana de açúcar e ao cacau. $\mathrm{O}$ Instituto do Açúcar e do Álcool (IAA) também foi criado no início dos anos 30 para lidar com a forte crise dos mercados internacionais e durou até o início da década de 1990, quando foi extinto, como o IBC. No caso do IAA, o minucioso estudo apresentado por T. Szmeráczanyi (1979) demonstra como uma organização pública, implantada por pressão de senhores-deengenho e de usineiros, instituiu controle preciso da produção de cana, da área plantada e da área cortada, das quantidades comercializadas em cada usina, através de sistemas de quotas, da quantidade de açúcar e álcool produzido por cada usina, dos preços pelos quais deveriam comercializar sua produção. Foi também esse organismo que esteve na origem de vários programas de modernização técnica da agroindústria do açúcar.

O caso do IAA revela bem como os detentores das plantations dispuseram de órgãos públicos que os protegiam da concorrência nacional e internacional: a diferença de produtividade dos rendimentos agrícolas entre o Centro-Sul e o Nordeste é uma constante de 1930 até 1990 (cf. T. Szmeráczanyi, 1979; A. Garcia Jr., 1990), mas tal diferença não acarretou a liquidação das unidades agroindustriais de menor produtividade, como teria ocorrido se prevalecessem condições de "concorrência pura e perfeita", como reza a teoria econômica neo-clássica. O IAA instituiu uma segmentação entre os mercados do Centro-Sul e os do Nordeste, estabelecendo sistematicamente preços mais elevados para esta última região na proporção de seus custos mais elevados. Houve assim, por mais de meio século, subsídios nos preços da cana e do açúcar. O IAA funcionou, por conseguinte, como um grande cartel, lastreado pelo Tesouro Nacional, que 
impediu as empresas mais ineficientes de arcarem com o ônus de sua ineficiência relativa (A. Garcia Jr., 1990). Tudo se passou, praticamente até a última década do século XX, como se as instituições públicas, criadas para impedir que a tendência à superprodução de lavouras comerciais acarretasse um aviltamento dos preços e para favorecer o incremento da produtividade agroindustrial, contribuíssem para perpetuar os mecanismos tradicionais de funcionamento e de gestão das plantações agroindustriais. É importante sublinhar que formas institucionais de ação pública como o IBC e o IAA estiveram muito mais ligadas à eternização de um Estado patrimonial, para usar as noções propostas por Raymundo Faoro, a partir dos conceitos propostos por Max Weber (1971), do que à construção de um Estado moderno promotor de padrões de eficiência empresarial do capitalismo contemporâneo. Os "donos do poder" (R. Faoro, 1958) tiveram em órgãos como o IBC e IAA alavancas poderosas para direcionar o processo histórico no ritmo da modernização conservadora, impedindo simultaneamente destinos mais favoráveis a reconversões que privilegiassem as camadas desfavorecidas que Ihes eram subordinadas. Mesmo assim, há uma multiplicidade das vias de transformação social do mundo rural, como veremos a seguir.

\section{A multiplicidade das vias de transformação no campo brasileiro}

As análises desenvolvidas até aqui permitem compreender que a abolição da escravatura significou, para os detentores de plantation, a perda do capital imobilizado em escravos, o que parece ter sido significativo em algumas regiões como o Vale do Paraíba do Sul (S. Stein, 1957), mas de forma alguma acarretou a ruína dos mecanismos para fazer prevalecer a autoridade de antigas famílias de senhores-de-engenho e fazendeiros sobre a mão de obra, que se via forçada a continuar a viver nos grandes 
domínios ou em suas periferias. Relações de dependência pessoal e de subordinação, como vimos nos casos de moradores e de colonos, foram recriadas permitindo a perpetuação de práticas anteriores de exercício do poder no interior das grandes propriedades (inclusive do poder de infligir castigos corporais aos subordinados). Essas formas de dominação personalizada que se generalizaram, na virada do século XIX para o século XX, supunham uma distribuição extremamente desigual do patrimônio fundiário, mas era através de práticas precisas de concessão do uso desse patrimônio que os grandes proprietários se constituíam uma clientela de famílias de trabalhadores submissa às suas ordens. Relembrando os termos de Robert Castel, a propriedade de si era de fato um privilégio das camadas superiores do espaço social.

As práticas de recrutamento e administração da força de trabalho das plantations tradicionais tornaram-se ineficazes ou mesmo contraproducentes diante dos efeitos combinados de quatro conjuntos de fatores: a) a evolução dos mercados internacionais das lavouras comerciais; b) a possibilidade de se emigrar para as metrópoles que industrializavam no sudeste do país - sobretudo São Paulo, Rio de Janeiro e Belo Horizonte; c) o surgimento de movimentos sociais camponeses, engendrando o reconhecimento do sindicalismo de trabalhadores rurais e a implantação de um novo quadro legal e institucional; d) a ampliação dos serviços educacionais e de saúde em meio urbano. Passemos em revista esses diversos fatores, responsáveis pela maior alteração morfológica da configuração cidade-campo: ainda em 1950, 64\% da população brasileira vivia no meio rural, enquanto, em 1980, só 32\% persistia habitando no campo. É notório que alteração de tal magnitude nas formas de viver e de trabalhar não pode ser explicada por uma pretensa "liberação da mão de obra" rural para setores industriais e de serviços mais produtivos localizados em meio urbano, pois uma constante deste processo foi a pauperização de largas parcelas dos contingentes submetidos à urbanização recente e os altos níveis de subemprego 
verificado nas metrópoles (para uma discussão sistemática ver Palmeira et al, 1977). Mais do que uma discussão simplista sobre a "modernidade" atingida pelo Brasil industrializado da segunda metade do século XX, esta verdadeira mutação social da sociedade brasileira exige que se examinem as modalidades das mudanças de horizontes sociais para milhões de indivíduos e suas relações com as transformações das formas de poder tanto em meio rural quanto em meio urbano.

O primeiro fator explicativo das mudanças sociais já foi estudado anteriormente: trata-se da evolução desfavorável dos preços obtidos pelas lavouras comerciais no mercado internacional e no mercado nacional, cujos choques foram grandemente amortecidos pela ação das instituições públicas como IBC, IAA e outras.

Um segundo fator decisivo para a alteração das formas de dominação tradicionais foi a possibilidade de emigrar em massa para as metrópoles que se industrializavam rapidamente desde os anos 30, como São Paulo e Rio de Janeiro. A migração não só forneceu aos novos capitalistas industriais mão-de-obra extremamente barata e disposta a aceitar condições de existência quotidianas penosas, como as que se verificam por exemplo nos canteiros de obras onde "dormem em rede pregada em qualquer canto", "comem nas latas", se cobrem "com qualquer trapo de roupa", que seriam inaceitáveis, caso os chefes de famílias trabalhadores tivessem que submeter o conjunto de seus grupos domésticos a tais "padrões urbanos" das metrópoles modernas (F. Oliveira, 1972). A migração também esteve na origem da acumulação de recursos materiais e culturais, à custa de muito sacrifício físico e psicológico, que permitiram a muitos descendentes de pequenos proprietários ou a ex-moradores escaparem das maIhas da submissão tradicional através da morada - escaparem da sujeição e se estabelecerem como pequenos proprietários, pequenos comerciantes ou profissionais por conta própria (pedreiros, bombeiros, eletricistas, etc.) em suas regiões de origem (A. Garcia Jr., 1989 e 1990). 
O terceiro fator impulsionador das mudanças morfológicas nas configurações cidade-campo no Brasil foi a modalidade mesma da implantação dos novos direitos trabalhistas herdados de dois séculos de lutas sociais na Europa (R. Castel, 1995). No caso brasileiro, como de outros países sulamericanos como o Chile (S. Gomez, 1982), houve uma segmentação dos modos de instituir normas e arcabouço jurídico para regular o mercado de trabalho: nas cidades foram implantadas leis (vide CLT de 1943) e criadas a justiça e a inspetoria do trabalho, nos momentos em que a industrialização por substituição de importações ganhava novo ritmo; o campo foi considerado como o universo do "usos e costumes", ou seja, das práticas de dominação tradicionais dos senhores de terra. Em verdade, o projeto inicial de Vargas parece ter sido o de estender aos trabalhadores do campo as vantagens concedidas aos trabalhadores urbanos. Contudo a oposição de representantes políticos ligados aos grandes plantadores foi tenaz e bloqueou qualquer tentativa de haver evolução simultânea das normas trabalhistas urbanas e rurais.

Foi a criação das "Ligas Camponesas" em meados dos anos 50, por Francisco Julião (1962 e 1968), em paralelo às organizações próximas ao Partido Comunista na ULTAB (União dos Lavradores e Trabalhadores Agrícolas do Brasil, cf. M. Grynszpan, 1987; L. Medeiros, 1989; J. S. Martins, 1981), que deu um impulso decisivo para que o Parlamento votasse finalmente o Estatuto do Trabalhador Rural em 1963 (A. Camargo, 1979); contribuiu para isso, também, o pânico que se alastrou pela classe dos grandes proprietários com os rumos tomados pela Revolução cubana em 1960 (M. Palmeira, 1977). Contudo é de se notar que a clientela das Ligas não era formada por assalariados rurais, mas por foreiros (F. Julião, 1968; B. Heredia, 1979; A. Garcia Jr., 1983), ou seja, por moradores de engenhos abandonados pelos descendentes de senhores-de-engenho. É quando tais descendentes decidem controlar novamente os domínios abandonados, e retomar práticas tradicionais de serviços gratuitos, na infra-estrutura da propri- 
edade, como o cambão, sem terem preenchido durante anos os requisitos de proteção dos moradores para serem considerados como bons patrões, que os antigos foreiros vão recorrer a um jovem advogado e deputado do PSB (Partido Socialista Brasileiro) para traduzir o conflito na justiça. Notese que Julião usou inicialmente apenas os dispositivos legais do Código Civil aprovado em 1916, tanto para caracterizar o caráter abusivo do trabalho gratuito (cambão) como lidar com a elevação do foro. Assim, as práticas jurídicas antecederam as decisões parlamentares: a tradução dos conflitos na justiça entre várias categorias subalternas e os grandes proprietários passou a atribuir um peso da palavra pública de camponeses, equivalente à de seus senhores, na prática dos tribunais era teatralizada a igualdade de cidadãos diante da lei. F. Julião lembra que as violências contra aqueles que davam início a uma "questão" na justiça, ou contra simples testemunhas, freqüentemente ocorriam depois que ocorrera a primeira audiência: é que os senhores-de-engenho sentiam-se humilhados ao verem que seus depoimentos tinham valor igual ao de seus adversários nos tribunais. Uma mesma lei para todos era inadmissível para quem se julgava único senhor em seus domínios, a igualdade de todos diante do direito rompia o véu que assegurava a hierarquia existente entre os que "tinham nome na praça" e a multidão dos "João ninguém".

Se as Ligas dominam o cenário político do surgimento do movimento camponês em final dos anos 50, não foram elas que mais contribuíram para disseminar o uso das leis trabalhistas e criar os novos sindicatos de trabalhadores rurais (A. Camargo, 1973; M. Palmeira, 1977): os vetores da aplicação dos novos dispositivos legais foram os grupos de sindicalistas católicos ou, então, os comunistas (G. Bezerra, 1979; J. Pureza da Silva, 1982); a concorrência pelo monopólio da representação profissional de um novo ator político - os "camponeses" ou os "trabalhadores rurais" provocou a consolidação, em larga escala, do sindicalismo camponês, com a criação de Federações estaduais e da CONTAG ainda em 1963, e contri- 
buiu decisivamente para a inscrição nas práticas sociais dos novos dispositivos legais.

A instauração do Direito do Trabalho modificou radicalmente as formas de construção da dominação pessoalizada até então prevalecente, já que ela introduziu um sistema de equivalências monetárias para tudo o que antes era objeto de trocas mediante e contradons. $\mathrm{O}$ novo direito tornava perigosas e mesmo ameaçadoras as estratégias tradicionais dos grandes plantadores, que tinham por finalidade endividar material e moralmente seus moradores e colonos. Segundo o novo sistema de normas jurídicas, todo trabalho efetuado para o patrão deve ser retribuído segundo o valor do salário mínimo, e todas as vantagens anexas, férias, repouso remunerado, décimo terceiro, são calculáveis pelos mesmos parâmetros; há também limites para descontos pelo fornecimento de moradia, assim como atribuição de lotes de subsistência e concessão de criar animais não podem dar lugar a contraprestações monetárias. O conjunto de práticas tradicionais não instaura mais uma dívida do dependente com o detentor da plantation, mas torna o grande proprietário devedor de seus dependentes, ao menos potencialmente.

Assim, as práticas e estratégias tradicionais de exibição da generosidade de "bons senhores" tenderam a se modificar radicalmente: se não expulsam as famílias residentes em seus domínios, não mais concedem morada a novos casais, nem os que os procuram vindo de outros domínios, nem os descendentes das famílias abrigadas na propriedade. Este verdadeiro movimento de "desconstrução" de relações sociais teve efeitos sobre a totalidade do espaço social, pois, mesmo para pequenos proprietários ou pequenos comerciantes se alteram as condições de reprodução de suas posições sociais. Foi, assim, o conjunto dos participantes das plantations tradicionais que se viu obrigado a gerir, em condições desiguais, segundo os recursos materiais e simbólicos de que dispunha cada indivíduo, a reconversão de suas posições, de suas práticas e de suas categorias de pensamento e de percepção do mundo social. 


\section{Desenraizamento das antigas clientelas rurais}

Cabe registrar que a maior parte dos antigos moradores e colonos foi submetida a um processo de pauperização, porque se viram expropriados de suas condições tradicionais de existência, sem que isso signifique que tenham se transformado em um novo proletariado rural, titular de direitos e obrigações.

Ao sair da propriedade, o trabalhador se via forçado a ter que assumir os custos materiais de uma nova morada, fosse ao pagar aluguel para prédios urbanos, fosse adquirir chão de casa para construir seu imóvel, fosse invadir terreno onde poderia estabelecer-se mesmo a título precário. Não dispunha mais do acesso à água e à lenha da antiga propriedade, que, nesta nova situação, tornavam-se novas mercadorias. Não dispunha ainda de sítios ou de terra para roçados onde pudesse cultivar na estação chuvosa as culturas alimentares: todo terreno de lavoura supunha agora contrapartida sob a forma de arrendamento ou meação: a terra impõe-se como mercadoria a todos. O terreiro em volta da moradia urbana não tem a amplitude nem o caráter aberto da situação de outrora: as mulheres não podem mais ter criação de cabras, porcos e aves como rezava a tradição. Assim, tudo o que antes era disponível como o ar que se respira, que só custava esforço e disposição para "o pesado", tornava-se mercadoria que exigia previamente alguns recursos monetários acumulados. Percebe-se, assim, que a reconversão objetivamente exigida dos trabalhadores e de suas famílias era de monta: o investimento material e psicológico requerido supunha uma história de acumulações de bens materiais e de experiências de gestão autônoma da economia familiar que só para parcelas restritas foi possível observar (cf. A. Garcia Jr., 1990). O deslocamento forçado para as cidades, porque os "patrões haviam ficado ruins" e não se revelaram mais "generosos" como no passado, foi assim vivido na grande maioria dos casos como um processo de perda, de decadência e, por isso mesmo, esteve 
freqüentemente associado a representações idealizadas do passado, como um tempo de fartura e harmonia, frente a um presente de privações e de incertezas (L. Sigaud, 1979).

Há, no processo histórico brasileiro, algo que nada tem de inexorável: a experiência da liberdade vem associada para a maioria da população à vivência de um empobrecimento material que limita evidentemente os investimentos culturais e de desenvolvimento da subjetividade.

A passagem do antigo sistema de relações, no qual os patrões se colocavam como "protetores" que tinham de prover o necessário ao sustento de seus dependentes e impunham suas normas à vida quotidiana, a outro universo caracterizado pela interdependência entre os indivíduos, sem ligação formal entre si, exige de cada qual, para empregar um conceito de Norbert Elias (1973), que se imponha uma «autodisciplina»; talvez possamos apenas imaginar as tensões acarretadas pela necessidade imperiosa de passar a gerir a própria existência sem o auxílio de ninguém, submetido a todas as urgências impostas pelas necessidades humanas mais imediatas, como a fome. Não é de espantar que tal situação desemboque freqüentemente em reativação de formas de dependência pessoal, em que a busca de nova proteção abrangente seja a contrapartida de uma fidelidade sem limites, o que pode ter lugar em organizações religiosas, redes de clientelismo político ou, ainda, em bandos armados ligados a tráficos de drogas.

É importante, contudo, ressaltar que o caráter maciço da transformação de antigos moradores, ou de colonos, em clandestinos de ponta-derua, ou em bóias-frias, não implica a inexistência de outros itinerários sociais quando se abandona a condição de dependente da grande lavoura: as migrações, tanto para as metrópoles industriais quanto para as regiões de fronteira do centro-oeste e da Amazônia nos anos 70, permitiam também uma mobilidade ascendente e estiveram na origem da formação de grupos de pequenos comerciantes e de profissionais por conta própria, além de 
um campesinato de fronteira (O. Velho, 1974). A análise das práticas e das representações sociais de famílias de migrantes revela que os deslocamentos para as metrópoles industriais (São Paulo, Rio de Janeiro, Belo Horizonte) possibilitaram que, numa mesma fratria, alguns irmãos obtivessem a condição de empregados com carteira assinada no centro-sul e aí passassem a morar em caráter definitivo, enquanto outros irmãos obtivessem, através de um emprego temporário como operário industrial, ou no setor de comércio e de serviços, os recursos materiais e culturais para adquirir uma pequena propriedade rural ou se instalar como pequeno comerciante em sua região de origem (A. Garcia Jr., 1990). As reconversões efetuadas através de migrações dependem tanto das condições do ponto de partida quanto das redes que são mobilizadas para que o deslocamento tenha sucesso (empreiteiros, redes familiares, grupos geracionais, etc.) e das condições de mercado de moradia e de mercado de trabalho do ponto de chegada (veja-se a excelente monografia de Marilda Menezes, 2002). Nada é tão variável quanto a situação de cada indivíduo concreto ao se deslocar, já que, dependendo de seu sexo, de sua idade, da condição familiar e posição no grupo assim constituído, de seus investimentos escolares e culturais passados, duas viagens entre os mesmos pólos podem ter significados totalmente diversos para a existência de um mesmo indivíduo.

\section{Origens sociais do movimento dos sem terra e os futuros alternativos do mundo rural}

Sem sombras de dúvidas, a mudança de atitude da Igreja Católica, na segunda metade do século XX, foi um dos fatores mais significativos do funcionamento do espaço político no Brasil. Como ressaltou Francisco Julião (1968), a Igreja Católica tinha virtualmente o monopólio da difusão das visões de mundo e de ritos religiosos no mundo rural brasileiro até os anos 50; não foi obra de acaso se socialistas e comunistas se uniram a pastores 
protestantes, como João Pedro Teixeira, fundador da Liga de Sapé na Paraíba, para dar origem ao sindicalismo camponês. É no final dos anos 60, particularmente após a decretação do ato institucional de $N^{\circ} 5$ (AI-5), quando as liberdades mais fundamentais são atingidas e a corporação militar dá início a práticas de tortura sistemática de adversários, que a hierarquia eclesiástica começará a criticar a ditadura e a se preocupar com a situação das classes populares tanto no campo quanto na cidade. Esta mudança que atingiu o clero do alto a baixo foi também impulsionada pela crescente concorrência religiosa, particularmente com o crescimento das igrejas pentecostais tanto no campo como na cidade (R. Novaes, 1985 e 1987). A implantação das "comunidades eclesiais de base" (CEB) por todo o país permitirá que, das discussões em grupos assim constituídos, surjam muitas das iniciativas de mobilizações populares por condições de vida mais dignas e a criação da "Comissão Pastoral da Terra", em 1975, tornou sistemático o trabalho de mobilização junto ao campesinato, desenvolvido pelos padres, bispos, agentes religiosos e catequistas. Como a Igreja Católica era a única corporação implantada em todos os pontos do território nacional, como a corporação militar, suas novas formas de proselitismo e recrutamento de fiéis abriram a possibilidade, durante os anos 70 de feroz repressão pelo regime militar, de uma discussão continuada e sistemática das dificuldades sociais impostas pelos rumos do processo de transformação social. Nota-se que, mesmo não-católicos como estudantes, intelectuais, militantes políticos, além de adeptos das mais diversas religiões, viram, na nova ação da Igreja Católica, um espaço seguro para retomar as tentativas de mobilizações populares; não foram poucos os que saíram das prisões para se integrarem em trabalhos juntos a setores populares através das CPTs e das CEBs.

A CPT atuou tanto como fonte autônoma de mobilizações camponesas, como em inúmeras lutas contra os despejos de posseiros e pela desapropriação de fazendas, particularmente em Mato Grosso, Goiás, no 
Maranhão e na Amazônia, quanto como força auxiliar do sindicalismo CONTAG ali onde ele era mais combativo, particularmente no caso de ocupações de fazendas e de greves de assalariados rurais posteriores ao congresso da CONTAG de 1979.7 Foi junto à CPT que se formavam as oposições sindicais que renovaram as lideranças do sindicalismo oficial, mesmo antes do fim do regime militar, e foi também aí que foram formadas as lideranças mais importantes do MST atual (B. Fernandes, 1996). Muitas ONGs que atuam agora no mundo rural brasileiro, tiveram também por origem a militância de estudantes e professores universitários, de advogados, de padres, freiras e agentes pastorais, junto aos grupos constituídos pelas CPTs e pelas CEBs nos anos 70 e 80. A mudança de orientação da Igreja Católica ao final dos anos 60, para o qual muito contribuiu a coordenação da hierarquia eclesiástica através da CNBB (Conferência Nacional dos Bispos do Brasil), foi um fator essencial para a reestruturação do espaço político brasileiro e teve um peso decisivo para o crescimento do movimento camponês e para a legitimação do tema da reforma agrária durante as três últimas décadas (cf. M. Palmeira, 1985).

Além da Igreja Católica, muitos outros grupos religiosos se implantaram e se difundiram por todo o país, principalmente recrutando fiéis entre as camadas mais pobres da população. A diversificação do campo religioso contribuiu acentuadamente para forjar novas percepções do futuro tanto ao nível individual quanto coletivo. O crescimento de grupos pentecostais entre camponeses conhecendo trajetória ascendente (R. Novaes, 1985) demonstra como a competição religiosa pode engendrar novas modalidades de elaboração de ethos e permitir a sacralização de solidariedades em bases diferentes do clientelismo patriarcal.

Não foram só as igrejas que conheceram um crescimento de seus templos e uma diversificação de suas atuações institucionais; enorme foi o crescimento do Estado nacional e grandes suas implicações para gerenciar as transformações do mundo rural. Em particular, cabe mencionar a cria-

7 Para uma análise das greves de canivieiros do Nordeste ver Lygia Siigaud (1980). 
ção de Universidades públicas em todo o território brasileiro e de instituições especializadas na pesquisa de biotecnologias como a EMBRAPA, ou em sua difusão como a EMATER. Esses organismos contribuíram para a profissionalização de cientistas das mais variadas disciplinas, nas quais as ciências sociais foram tão beneficiadas como as "ciências da terra" e as biológicas, e se forjaram, assim, instrumentos para imprimir novos rumos às transformações do mundo rural. À diferença de orgãos como IBC, IAA e outros, a pesquisa científica que se desenvolveu nessas outras instituições públicas não estava subordinada a interesses de elites profissionais de grandes plantadores. Como no caso da diversificação do campo religioso, a autonomização e a diversificação do campo científico está na origem de novos instrumentos para tentar imprimir novos rumos às transformações do mundo rural. O elenco das vias de mudanças possíveis parece estar-se ampliando, o debate recente demonstra que os processos em curso não estão submetidos nem a determinismos econômicos nem a determinismos de qualquer outra ordem.

A retomada das ocupações de terra, sobretudo pelo MST, desde o final dos anos 80, assim como a aceleração dessas ações durante os anos 90, vão demonstrar que os conflitos fundiários existem no país inteiro, que há milhões de demandantes de terra para nela fixaram residência e dela tirarem ao menos parte de seu sustento, mas essa demanda que não se exprime no mercado fundiário pode ser materializada no sacrifício dos acampamentos, das longas marchas, das romarias. Das formas mais variadas, os descendentes de senzalas, ou de seus sucedâneos, passaram a exibir sua pobreza e sua obstinação em não se deixar excluir da vida social: foram os antigos senhores que adquiriram a liberdade ante as suas antigas clientelas, a liberdade de lhes negarem abrigo e sustento material, de lhes negarem o reconhecimento social de que merecem ter existência digna como qualquer cidadão de Estado democrático. O fim do patrão tradicional não supõe o surgimento do "homem solidário"? Ou, em vocabulário 
próximo de Robert Castel: o fim das proteções de proximidade não implica a "invenção do social", ou o Estado social, para atenuar os efeitos devastadores do desenraizamento de populações camponesas?

Com a expansão do número de engenhos e fazendas transformadas em assentamentos, ganhou força o debate sobre a relevância da "agricultura familiar", ou, mais precisamente, das estratégias de reconversão de populações desprovidas de recursos, que supõem o uso intensivo da força de trabalho do grupo doméstico, ou ainda, de desenvolvimento de pequenos e médios proprietários que utilizam sobretudo membros de seus grupos familiares. Cabe aqui dialogar com as preocupações externadas pela Professora Magdalena León, pois, ao falar de agricultura familiar, muitos autores pretendem referir-se a novo ator do cenário político, econômico e cultural do país, como se toda a diversidade de categorias efetivamente já estudadas pela sociologia rural e antropologia do campesinato, como sitiantes, posseiros, pequenos proprietários, lavradores, parceiros, arrendatários, etc. pudesse ser realizada e subsumida sob essa única rubrica conceitual. $\mathrm{O}$ adjetivo familiar justaposto à categoria agricultores aparece sobretudo como um meio de designar um agente social diferente de agricultores patronais, no qual a referência se esgota nas diferenças entre o chefe da exploração agrícola (patrão oposto a pai ou mãe de família) e seus subordinados (assalariados opostos a filhos/filhas). Tudo indica, ao contrário, que a rede familiar característica do universo rural brasileiro apresenta uma configuração própria de relações de aliança e de filiação específicas e diversificadas a exigir um exame mais minucioso de antropólogos e sociólogos rurais. O reducionismo político ou jurídico da categoria agricultores familiares demonstra, ainda uma vez, como análises sociológicas tem sido tributárias de uma subordinação às demandas do campo político e ideoló-

8 Para que tal afirmação apareça como vaga e abstrata, basta observar o documento instituidor de um programa de crédito tão inovador como o PRONAF. Diferem-se aí três categorias de agricultores familiares quantificando os efetivos do mundo rural, habituado a constatar como o crédito subsidiado foi privilégio dos grandes proprietários durante o regime militar, além da alavanca poderosa da modernização conservadora (cf. Guilherme Delgado, 1985), a categoria mais numerosa é sumariamente estigmatizada como inviável. Resta saber, ângulo ligeiramente menos economicista, se os autores de tal proposta julgam verdadeiramente que tal parte da população brasileira é composta por famílias inviáveis. 
gico. ${ }^{8}$ A criação de uma política de crédito específica, como o PRONAF (Programa Nacional de Apoio à Agricultura Familiar), contribuiu ainda para legitimar novas modalidades de agricultores.

A diversidade de designações para as unidades agrícolas demonstra que vários atores disputam, dentro do mundo rural e dentro do campo político, o reconhecimento para os projetos de futuro que contemplem mais de perto seus próprios interesses. O projeto recente do governo, que discorre sobre o "novo mundo rural", não escapa dessas formas de competição por designar o futuro da coletividade sob a aparência de designar um destino inexorável. Como para Austin, dizer é fazer.

Não cabe aos sociólogos a postura de falsos "videntes do futuro", ou ainda de profetas de paraísos imaginários. Há cem anos atrás, o escritor brasileiro Euclides da Cunha, através do relato da guerra de Canudos (189397), retraçava a tragédia causada pela arrogância dos que supunham deter a chave única do "jardim do Éden" da modernidade. Em suas próprias palavras:

E quando pela nossa imprevidência inegável deixamos que entre eles se formasse um núcleo de maníacos, não vimos o traço superior do acontecimento. Abreviamos o espírito ao conceito estreito de uma preocupação partidária. Tivemos um espanto comprometedor ante aquelas aberrações monstruosas e, com arrojo digno de melhores causas, batemo-nos a carga de baionetas, reeditando por nossa vez o passado, numa entrada inglória, reabrindo nas paragens infelizes as trilhas apagadas das bandeiras... Vimos no agitador sertanejo, do qual a revolta era um aspecto da própria rebeldia contra a ordem natural, adversário sério, estrênuo paladino do extinto regimen, capaz de derruir as instituições nascentes. 
E Canudos era a Vendéia... (Cunha, 1966 [1902], parte

II, capítulo V, p. 231).

As lições da história secular revelam que futuros que não recriem as hierarquias e as distâncias sociais fundadas à época de casas-grandes e de senzalas, que não recriem os poderes dos homens cordiais, supõem que nos debrucemos atentamente sobre as experiências dos que tentaram e tentam buscar praticamente e imaginar formas de convivência social em que a igualdade dos indivíduos seja regra quotidiana. Se contribuirmos dessa maneira como parceiros da consolidação de tais rumos, permitiremos talvez que se esmaeça a trágica imagem cunhada por Eduardo Galeano das "veias abertas da América Latina", para poder trilhar de maneira confiante, em época de tão avassaladora ofensiva de uma "restauração conservadora" (cf. Pierre Bourdieu, 1998), as "vias abertas pela América Latina".

\section{Referências}

ABRAMOVAY, A. Paradigmas do capitalismo agrário em questão. Campinas: UNICAMP, 1991.

ABREU, M. A ordem do progresso. Cem anos de política econômica republicana. Rio de Janeiro: Ed. Campus, 1990.

ALMEIDA, J. A. Memórias: antes que me esqueça. Rio de Janeiro: Francisco Alves, 1976.

ANTONIL, A. J. Cultura e opulência do Brasil. São Paulo: Editora Itatiaia/Editora USP, 1982 (Coleção Reconquista do Brasil, v. 70).

BACHA, E. 150 anos de café. Rio de Janeiro: Marcellino Martins e Johnston Exportadores, 1992.

BASTIDE, R. Le candomblé de Bahia. Paris, La Haye: Mouton, 1958.

BEZERRA,G. Memórias. Rio de Janeiro: Civilização Brasileira (2 vols ), 1979.

BUARQUE de HOLANDA, S. Raízes do Brasil. Rio de Janeiro: José Olympio, 1936. 
CAMARGO, A. Brésil Nord-Est: mouvements paysans et crise populiste. Thèse de $3^{\text {ème }}$ cycle. Paris: EHESS, 1973.

CAMARGO, A. A questão agrária: crise de poder e reformas de base. Rio de Janeiro: FGV, 1979.

CANDIDO, Antonio. O significado de Raízes do Brasil. In: Raízes do Brasil. Rio de Janeiro: José Olympio, 1967.

CASTEL, R. Les métamorphoses de la question sociale. Une chronique du salariat. Paris: Fayard, 1995.

CORREIA de ANDRADE, M. Terra e homem no Nordeste. São Paulo: Brasiliense, 1964.

CUNHA, E.. Os Sertões. Rio de Janeiro: Ed. Laemmert, 1902.

DAMATTA, R. Carnavais, malandros e heróis: para uma sociologia do dilema brasileiro. Rio de Janeiro: Zahar, 1979. 271 p.

DAVATZ, T. Memórias de um colono no Brasil. São Paulo: Itatiaia/Edusp, 1941.

DEAN, W. Rio Claro: um sistema brasileiro de grande lavoura 1820-1920. Rio de Janeiro: Paz e Terra, 1977.

DELGADO, G. C. Capital financeiro e agricultura no Brasil 1965-1985. São Paulo: Icone/UNICAMP, 1985.

DREYFUS, R. A conquista do Estado, Ação política, poder e golpe de classe. Petrópolis: Vozes, 1981 [1964].

EISENBERG, P. Modernização sem mudança: a indústria açucareira em Pernambuco 1840-1910. Rio de Janeiro: Paz e Terra/UNICAMP, 1977.

ELIAS, N. La civilisation des mœurs. Paris: Calmann-Lévy, 1973.

FAORO, R. Os donos do poder, formação do patronato político brasileiro. São Paulo: Companhia Editora Nacional, 1958.

FAUSTO, B. A revolução de 1930: historiografia e história. São Paulo: Brasiliense, 1970. 
FERNANDES, B. M. MST, formação e territorialização. São Paulo: Hucitec, 1996.

FREYRE, G. Casa-grande e senzala. Rio de Janeiro: Maia Schmidt, 1933.

FREYRE, G. Sobrados e mucambos. São Paulo: Companhea Editora Nacional, 1936.

FURTADO, C. Formação econômica do Brasil. Rio de Janeiro: Ed. Fundo de Cultura, 1959.

GARCIA Jr. A. Salário e campesinato. In: R. Novaes (org.) Encontros sobre a realidade nordestina. Campina Grande: UFPb, 1980.

GARCIA Jr., A. Terra de trabalho. Rio de Janeiro: Paz e Terra, 1983.

GARCIA Jr., A. Libre et assujetis. Paris: Ed. de la Maison des Sciences de I'Homme (Collection Brasília), 1989.

GARCIA Jr., A. O sul: caminho do roçado. São Paulo/Brasília: Marco Zero/UnB/ CNPq, 1990.

GARCIA, M. F. O Bacurau. Dissertação de mestrado apresentada ao PPGAS da UFRJ. Rio de Janeiro: Museu Nacional, 1977.

GARCIA Jr., A. ; Mário Grynszpan. Veredas da questão agrária e os enigmas do grande sertão. In: S. Miceli (org.). O que ler em ciências sociais. São Paulo: ANPOCS, 1999.

GOMES da SILVA, J. Caindo por terra. Crises da reforma agrária na Nova República. São Paulo: Busca Vida, 1987.

GOMEZ, S. Processos agrários in Chile. Santiago: 1982.

GRAZIANO da SILVA, J. A modernização dolorosa. Rio de Janeiro: Zahar, 1982.

GRYNSZPAN, M. Mobilização camponesa e competição política no Estado do Rio de Janeiro. Dissertação de mestrado apresentada ao PPGAS da UFRJ. Rio de Janeiro: Museu Nacional 1987.

B. HEREDIA. Morada da Vida. Rio de Janeiro: Paz e Terra, 1979.

B. HEREDIA. Formas de dominação e espaço social. Rio de Janeiro: Paz e Terra, 1989. 
Sociologias, Porto Alegre, ano 5, no 10, jul/dez 2003, p. 154-189

HOLLOWAY, T. Vida e morte do convênio de Taubaté. Rio de Janeiro: Paz e Terra, 1968.

INCAO, M. C. O bóia-fria: acumulação e miséria. Petrópolis: Vozes, 1975.

JULIÃO, F. Cambão, la face cachée du Brésil. Paris: Maspero, 1968.

KULA, W. Théorie économique du système féodal. Paris-La Haye: Mouton, 1970.

LEITE LOPES, J. S. Vapor do diabo: o trabalho dos operários do açúcar. Rio de Janeiro: Paz e Terra, 1976.

MARTINS, J. S. O cativeiro da terra. São Paulo: Ed. Ciências Humanas, 1979.

MARTINS, J. S. Os camponeses e a política no Brasil. Petrópolis: Vozes, 1981.

MATTOSO, K. Bahia, uma província no Império. Rio de Janeiro: Ed. Record, 1992.

MEDEIROS, L. História dos movimentos sociais no campo. Rio de Janeiro: FASE, 1989.

MONBEIG, P. Pionniers et planteurs à São Paulo. Paris: Armand Colin, 1952.

MUSUMECI, L. O mito da terra liberta. São Paulo: ANPOCS/Vértice, 1988.

NOVAES, R. Os escolhidos de Deus. Rio de Janeiro: Marco Zero/ISER, 1985.

NOVAES, R. De corpo e alma. Tese de doutoramento. São Paulo: Departamento de Ciências Sociais da USP, 1987.

OLIVEIRA, F. A economia brasileira: crítica à razão dualista. In: Estudos CEBRAP, n. 2, outubro, 1972, p. 3-82.

PAIVA, R. M. «Reflexões sobre as tendências da produção, da produtividade e dos preços do setor agrícola no Brasil» e «Bases para uma política para a melhoria da agricultura brasileira». In: F. Sá (Org.) Agricultura subdesenvolvida. Petrópolis: Vozes, 1968, p. 167-261.

PAIVA, R. M. Os baixos níveis de renda e salários na agricultura. In: Estudos Agrários, Rio de Janeiro, INCRA, n. 0, 1976. 
PALMEIRA, M. Feira e mudança econômica. In: Simpósio de Pesquisas do PPGAS, Rio de Janeiro: Museu Nacional, 1970 (mimeo).

PALMEIRA, M. Latifundium et capitalisme: lecture critique d'un débat. Thèse de doctorat. Paris: EHESS, 1971.

PALMEIRA, M. Casa e trabalho: nota sobre as relações sociais na plantation tradicional. In: Congrès international des américanistes, Paris, n. 42, (2-9 septembre), 1976.

PALMEIRA, M. The aftermath of peasant mobilization: rural conflicts in the Brazilian Northeast since 1964. In: N. Aguiar (org.) The structure of Brazilian developement. New Brunswick, NJ: Transaction Books, 1977.

PALMEIRA, M.; LEITE, S. Debates econômicos, processos sociais e lutas políticas: reflexões sobre a questão agrária. In: Debates CPDA, Rio de Janeiro, UFRRJ, n. 1 setembro, 1997.

PALMEIRA, M. et al. Projeto Emprego e mudança socio-econômica no Nordeste. In: nuário Antropológico 76. Rio de Janeiro: Tempo Brasileiro, 1977.

PALMEIRA, M.; WAGNER de ALMEIDA, A. A invenção da migração. In: Projeto emprego e mudança sócio-econômica no Nordeste. Convênio UFRJ/FINEP/IPEA/ IBGE, relatório final, vol. 1. Rio de Janeiro: Museu Nacional, 1997.

PRADO, Jr. C. Formação do Brasil Contemporâneo. São Paulo: Martins Fontes, 1942.

PUREZA da Silva, J. Depoimento. In: O. Dwyer (org). Memória camponesa. Rio de janeiro: Marco Zero, 1982.

RANGEL, I. A questão agrária brasileira. Recife: Comissão de Desenvolvimento de Pernambuco, 1962.

RANGEL, I. A inflação brasileira. Rio de Janeiro: Tempo Brasileiro, 1963.

RINGUELET, R. Los migrantes estacionales del Nordeste. Dissertação de mestrado apresentada ao PPGAS da UFRJ. Rio de Janeiro: Museu Nacional, 1977.

SACHS, I. Tristes tropiques ou terre de bonne espérance. In: Hérodote (numéro intitulé «La Nation Brésil») n. 98, septembre, 2000. 
SACHS, I. Amazônia: problema e solução. In: Política Externa. Brasília, v. 10, n. 2, 2000 .

SAYAD, A. L'immigration ou les paradoxes de l'altérité. Bruxelles: De BoeckWesmael, 1991.

SEYFERTH G. A colonização alemã no vale do Itajaí-mirim. Porto Alegre: Editora Movimento, 1974.

SIGAUD, L. A percepção dos salários entre trabalhadores rurais. In: P. Singer (org.). Capital e trabalho no campo. São Paulo: Hucitec, 1977.

SIGAUD, L. Os clandestinos e os direitos. São Paulo: Duas Cidades, 1979.

SIGAUD, L. A Nação dos Homens. In: Anuário Antropológico, n. 78, Rio de Janeiro, Tempo Brasileiro, 1980, p 13-114.

SILVA, S. Expansão cafeeira e origens da indústria no Brasil. São Paulo: AlfaOmega, 1976.

STEIN, S. Vassouras a brazilian coffee country 1850-1900. Cambridge/ Massachusetts: Harvard Historical Studies, 1957.

STOLCKE, V. Cafeicultura. São Paulo: Editora Brasiliense, 1976.

SZMERECSÁNYI, T. O planejamento da agroindústria canavieira do Brasil (193075). São Paulo: Hucitec-Unicamp, 1979.

TAVARES dos SANTOS, J. V. Colonos do vinho. São Paulo: Hucitec, 1978.

TAVARES, M. C. Da substituição da importação ao capitalismo financeiro. Rio de Janeiro: Paz e Terra, 1972.

THÉRY, H. Le Brésil. Paris: Armand Colin, 2000

WAGNER de ALMEIDA, A. GETAT: a segurança nacional e o revigoramento do poder regional. São Luís: CPT-Maranhão, 1980. 
WEBER, M.. Economie et société. Paris: Plon, 1971.

WILKINSON, J. Estudo da competitividade da indústria brasileira: o complexo agroindustrial. Rio de Janeiro: Forense Universitária, 1996.

WOLF, E.; MINTZ, S. Haciendas, latifundios y plantaciones en América Latina. In: Florescano (org.). México: CLACSO/Siglo XXI, 1975.

VELHO, O. Frente de expansão e estrutura agrária. Rio de Janeiro: Zahar, 1970.

VELHO, O. Capitalismo autoritário e campesinato. São Paulo: Difel, 1974.

\section{Resumo}

O trabalho examina os diferentes itinerários seguidos por descendentes dos senhores, proprietários de haciendas ou de grandes plantações integradas ao mercado internacional, e descendentes de escravos ou de camponeses submetidos a relações de subordinação, numa perspectiva da cidadania política. A análise abrange a grande lavoura como matriz da sociabilidade hierárquica herdada da época colonial, os principais fatores responsáveis pela quebra das condições de existência da dominação tradicional, as modalidades de desenraizamento do campesinato brasileiro e as mobilizações promovidas pelo movimento dos semterra e da busca de novas formas de enraizamento social e cultural de camadas desfavorecidas.

Palavras-chave: migração, luta pela reforma agrária, campesinato brasileiro, cidadania política. 